\title{
Repeatability of the Universiti Teknologi MARA reading Charts Buari $\mathrm{NH}^{1}$, Yusof $\mathrm{NH}^{2}$, Mohd-Satali $\mathrm{A}^{3}$, Chen $\mathrm{AH}^{4}$
}

\begin{abstract}
:
Objective: This study was done to investigate the repeatability measurements in reading rate using the Universiti Teknologi MARA Malay related words (UiTM-Mrw) reading chart and Universiti Teknologi MARA Malay unrelated words (UiTM-Muw) reading chart. Methodology: Thirty normally sighted participants were randomly recruited through randomised sampling (mean age $=21.5 \pm 1.1$ years). Participants were instructed to read aloud, clearly and as quickly as possible at 2 different sessions using two different charts. The two charts were selected at random sequence. A minimum of 7 days interval was used to minimizethe learning affect. The time taken to read each chart was recorded and any errors while reading was noted. Reading performance was quantified as reading rate in words per minute (wpm). Results: Comparison of reading rate between session 1 and session 2 was not significantly $\operatorname{different}(\mathrm{p}=0.894, \mathrm{df}=1$, $\mathrm{F}=0.018$ ) for UiTM-Mrw reading chart. The reading rate between session 1 and 2 also showed no significant difference $(\mathrm{p}=0.99, \mathrm{df}=1, \mathrm{~F}=2.811)$ in UiTM-Muw reading chart. Intraclass correlation coefficient (ICC) showed a good consistency in repeatability for both UiTM-Mrw reading chart and UiTM-Muw reading chart with ICC values of 0.849 and 0.814 respectively. The Bland and Altman plot between measurement of reading rate in session 1 and session 2 showed a good agreement in UiTM-Mrw reading chart and UiTM-Muw reading chart. Conclusion: Both UiTM-Mrw reading chart and UiTM-Mur reading chart showed a good consistency and good agreement in repeated measurement of reading rate.
\end{abstract}

Keywords: reading chart; reading rate; repeatability

Bangladesh Journal of Medical Science Vol.14(3) 2015 p.236-240 DOI: http://dx.doi.org/10.3329/bjms.v14i3.18964

\section{Introduction}

Reading is one of the important evaluations in quality of life.It was foundto affect the quality of life especially among those with vision impairment ${ }^{1-4}$. The reading performance was one of the important aspects of the evaluation in eye examination ${ }^{5}$. It should be done in a standardized technique and repeatable to monitor the visual performancewith time.

Reading performance should be evaluated using the reading chart to represent real reading condition. Routine near visual acuity measurement using Snellen notation had shown low correlation and can only predicted 10 percent of individual reading speed because it only involved recognition of single letter rather than giving real reading information ${ }^{6}$. Reading is a complex processes that involves decoding and linguistic comprehension components in acquiring meaning from printed or written words ${ }^{7}$. Among all available reading chart, there were MNRead acuity chart ${ }^{8}$, the practical near acuity chart ${ }^{9}$, Radner reading chart ${ }^{10}$, Bailey-Lovie reading chart ${ }^{11}$ and many more.

Most of the reading charts available were the English reading charts. It would be beneficial if there were a reading chart in Malay language to be used among Malay native speakers. The Universiti Teknologi MARA reading charts were set in two types which were the Universiti NNTeknologi MARA Malay related words (UiTM-Mrw) reading chart and

1. Noor Halilah Buari

2. Nur Hidayah Yusof

3. Adib Mohd-Satali

4. AI-Hong Chen Optometry

Faculty of Health Sciences, UniversitiTeknologi MARA(UiTM) PuncakAlam Campus, 42300, Selangor, Malaysia.

Corresponds to: Prof. Dr. Ai-Hong Chen, Optometry, Faculty of Health Sciences, UniversitiTeknologi, MARA, 42300 Bandar PuncakAlam, Selangor, Malaysia. Email: aihong0707@yahoo.com 
the Universiti Teknologi MARA Malay unrelated words (UiTM-Muw) reading chart. Reading speed of both UiTM-Mrw and UiTM-Muw reading chart was comparable with MNRead acuity chart and Colenbrander reading chart ${ }^{12,13}$.

The repeatability of clinical measurement is importance to be assessed in order to produce a good reliability and consistent outcomes. Any new reading chart will be tested its test-retest reliability as in previous studies ${ }^{14-18}$. In this study, the UiTMMrw reading chart and UiTM-Muw reading chart were investigated for reliable repeatable outcomes in clinical use by analyzing the test-retest of reading rate in Malay language.

\section{Materials and methods}

\section{Participants}

Thirty normally sighted young university students (mean age: $21.5 \pm 1.1$ years old) were volunteered to participate in this study through randomized sampling with informed consent. A screening test was conducted prior to the reading performance evaluation. The screening tests involves distance visual acuity test using the LogMAR visual acuity test chart (Lighthouse $2^{\text {nd }}$ Edition) at 4 meters. The Royal Air Force (RAF) rule was used to measure the remote near point of convergence and near point of accommodation. The inclusion criteria for this study were distance visual acuity of $6 / 9$ with habitual correction, no convergence and accommodation problem, fluently read the Malay and English reading material and the absence of eye pathology that can affect reading performance. This study adhered to the tenets of the Declaration of Helsinki and was approved by the Research Ethics Committee and approved by the UiTM ethic committee.

\section{The Universiti Teknologi MARA reading chart}

The Universiti Teknologi MARA Malay related word reading chart (UiTM-Mrw) (Figure 1(a)) and Universiti Teknologi MARA Malay unrelated word reading chart (UiTM-Muw) (Figure 1(b) were both

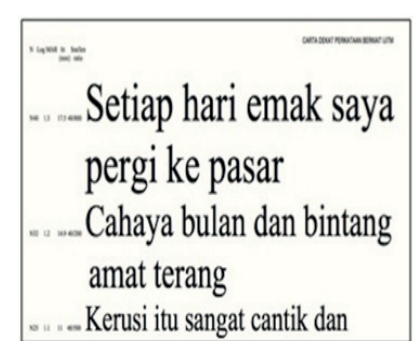

(a)

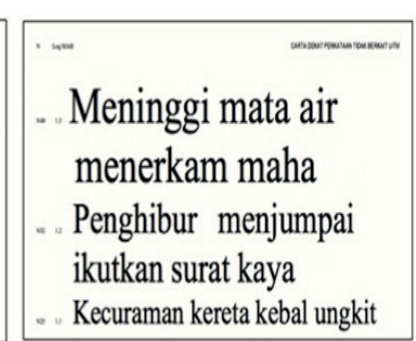

(b)
Figure 1: The UiTM reading charts (a) The UiTM Malay related words reading chart (b) The UiTM Malay unrelated word reading chart using the print sizes ranging from 1.3 LogMAR (N40) to 0.0 LogMAR (N1). A maximum of 60 characters per sentence was used (5 to 10 standardlength words). They were fourteen sentences in the sets of related words and unrelated words. The sentences for UiTM-Mrw reading chart were constructed based on from Grade 3 to 6 Malay school textbooks, whereby for UiTM-Muw reading chart the words were randomly selected from Daftar Kata Bahasa Melayu Sekolah Kebangsaan. The Daftar Kata Bahasa Melayu Sekolah Kebangsaan is the registry for Malay language words for primary schools. The related words set was constructed to mimics real reading activity. The unrelated words were constructed in meaningless sentence to remove any cues in reading process ${ }^{19}$. The font typeface used was "Times new roman" ${ }^{20}$. The sentences were aligned to the left and printed in $100 \%$ contrast.

Figure 1: The UiTM reading charts (a) The UiTM Malay related words reading chart (b) The UiTM Malay unrelated word reading chart

\section{Study protocols}

The participants were instructed to read loudly the UiTM-Mrw chart and UiTM-Muw chart at random sequence. The UiTM reading chart was placed at $40 \mathrm{~cm}$ on an inclined reading stand at 45 degree. The reading chart was covered prior to the start of reading performance evaluation. The participants were instructed to read the charts from the largest print to the smallest print. The time taken to read was recorded to the nearest $0.1 \mathrm{~s}$ and any errors in reading such as omission, missing the words were recorded. Reading rate was calculated in words per minutes $(\mathrm{wpm})^{21}$. The participants were asked to come again for second reading performance evaluation with a 7-day interval from the first session of evaluation.

\section{Statistical analysis}

Analysis was done using SPSS version 21 and Medcalc version 12 . The repeatability of reading rate for UiTM-Mrw chart and UiTM-Muw chart were analyzed using One-wayANOVA, intraclass correlation coefficient (ICC) and Bland-Altman plot.

\section{$\underline{\text { Results }}$}

\section{Reliability of repeatability}

The reading rate of UiTM-Mrw reading chart and UiTM-Muw reading chart for session 1 and session 2 was summarized in figure 2. The mean reading rate of UiTM-Mrw reading chart for session 1 and session 2 was $208.9 \pm 36.4 \mathrm{wpm}$ and $205.7 \pm 29.4 \mathrm{wpm}$ respectively. The UiTM-Muw reading chart showed the mean reading rate of $116.4 \pm 18.3 \mathrm{wpm}$ during session 1 and $124.3 \pm 17.7$ wpm during session 2 . 
The repeatability of reading rate for both UiTMMrw reading chart and UiTM-Muw reading chart were analyzed using one-way ANOVA and intraclass correlation coefficient (ICC). One-way ANOVA showed no significant difference $(\mathrm{p}=0.89, \mathrm{df}=1$, $\mathrm{F}=0.02$ ) on mean reading rate between reading performance evaluation on session 1 and session 2 for the UiTM-Mrw reading chart. No significant difference $(p=0.99, d f=1, F=2.81$ ) also was found in comparison of reading rate of UiTM-Muw reading chart between evaluation on session 1 and session 2. The comparison of reading rate between reading performance evaluation on session 1 and session was described in figure 2. The reliability of repeatability measurement in reading performance evaluation for UiTM-Mrw reading chart and UiTM-Muw reading chart were determined using intraclass correlation coefficient (ICC).

The reliability of repeatability for UiTM-Mrw reading chart and UiTM-Muw reading chart was good with ICC Chronbach's alpha value of 0.85 $(95 \%$ CI: lower bound $=0.68$; upper bound $=0.93$ ) and 0.81 (95\% CI: lower bound $=0.61$; upper bound $=0.91)$ respectively.

\section{Agreement of repeated measurements}

Figure 3: (a) Bland and Altman plot of reading rate between session 1 and 2 for UiTM-Mrw reading chart (b) Bland and Altman plot of reading rate between session 1 and 2 for UiTM-Muw chart.

The agreement of reading rate for UiTM-Mrw reading chart and UiTM-Muw reading chart were determine using Bland-Altman plot ${ }^{22-24}$ as in figure 3. Three lines are displayed on the Bland-

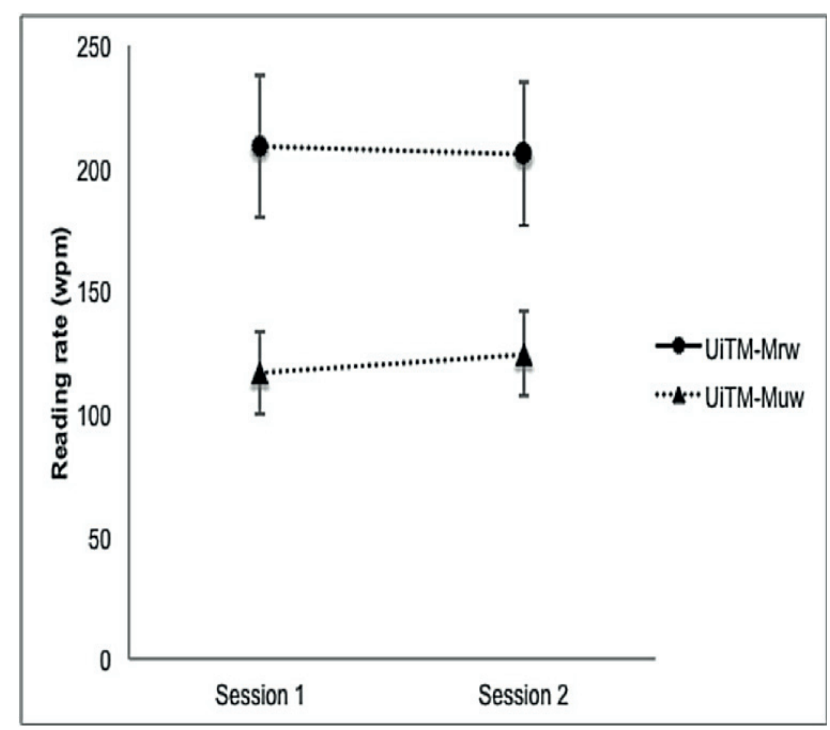

Figure 2: Comparison of reading rate for UiTM-Mrw chart and UiTM Muw chart between session 1 and session 2
Altman plot. The thick blue line represents the mean difference of reading rate between two sessions, the upper and lower red dash lines represent the 95\% limit of agreement $( \pm 1.96 \mathrm{SD})$. The agreement of reading rate for UiTM-Mrw reading chart between session 1 and session 2 showed a good agreement (figure 3a). The mean difference, lower limit and upper limit of reading rate for UiTM-Mrw reading chart were $1.1 \pm 8.95 \mathrm{wpm},-45.9 \mathrm{wpm}$ and $48.1 \mathrm{wpm}$ respectively. The reading rate evaluation in session 1 and session for UiTM-Muw reading chart showed a good agreement as shown in figure $3 \mathrm{~b}$. The mean difference, lower limit and upper limit of reading rate for UiTM-Mrw reading chart were-7.8 $\pm 14.3 \mathrm{wpm}$, $-36.0 \mathrm{wpm}$ and $20.3 \mathrm{wpm}$ respectively.

\section{Discussion}

Both UiTM-Mrw reading chart and UiTM-Muw reading chart showed no significant difference in reading rate between two sessions, good consistency in repeatabilityand good agreement in test-retest measurement in reading rate. Therefore, the reading rate measurements using UiTM-Mrw reading chart and UiTM-Muw reading chart were repeatable in normal-sighted young adults.

MNRead chart was found repeatable with the mean different of $\pm 8.6 \mathrm{wpm}^{14}$. On the repeatability study of MNRead acuity chart, the reading speed during session 1 and session 2 were 211.8 wpm and 210.4 wpm respectively. The reading speed of MNRead acuity chart was similar with the reading rate of UiTM-Mrw reading chart that were $206.9 \mathrm{wpm}$ and $205.7 \mathrm{wpm}$ and the mean difference of $\pm 8.95 \mathrm{wpm}$. Both UiTM-Mrw reading chart and MNRead acuity chart involved related words where the words were constructed in the form of sentence. Furthermore, Subramanian and $\operatorname{Pardhan}^{14}$, established the repeatability of MNread acuity chart used similar criteria for subject recruitment (young university student aged 18 to 30 years) as in this study. High repeatability in maximum reading speed of Italian version of MNRead chart were found with the mean difference of $\pm 0.077 \mathrm{wpm}^{15}$, which were lower than Malay version (this study) and English version ${ }^{14}$ Possible reason in the disparity of the outcome was younger participant than in this study since they used the children from Grade 3 to Grade $8{ }^{15}$.

Even though the UiTM-Muw reading chart showed a good repeatability, the reading rate was lower than MNRead acuity chart ${ }^{14}$. This was because reading the meaningful sentences will give an advantages of guessing cues for next word therefore the reading speed was higher than reading the unrelated words ${ }^{19}$. 

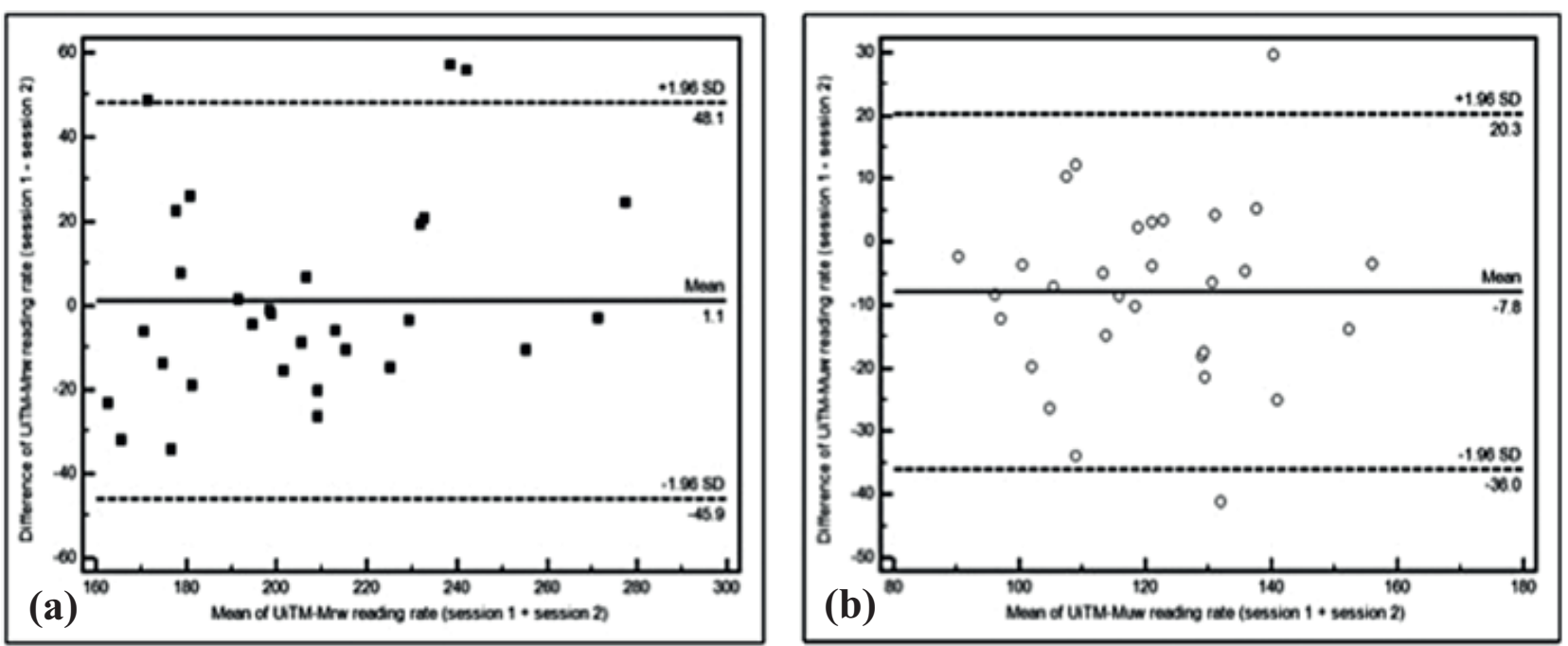

Figure 3: (a) Bland and Altman plot of reading rate between session 1 and 2 for UiTM-Mrw reading chart (b) Bland and Altman plot of reading rate between session 1 and 2 for UiTM-Muw chart.

The reading rate among Malay speaker was reported to be $103.9 \pm 32.0 \mathrm{wpm}^{25 \mathrm{n}=193}$, and similar with the reading rate of the UiTM-Muw reading chart i.e $116 \mathrm{wpm}$ for session 1 and $124 \mathrm{wpm}$ for session 2. The similarity in both reading rate was because the Malay reading text used in this previous study was also constructed using unrelated words.

Test-retest reliability of German Radner Reading chart showed high reliability and good reproducibility between two sessions ${ }^{16}$. The same goes with Dutch Radner reading chart ${ }^{17}$, which they found a good reliable test-retest and good agreement in reading speed among participants with low vision. In this study the ICC showed high reliability in the repeated measurements of the reading rate in the UiTM-Mrw reading chart as well as the UiTM-Muw reading chart i.e 0.85 and 0.81 respectively. Most of the testretest measurement in reading analyzed using the intraclass correlation coefficient to test the reliability of the repeated measurements ${ }^{14,15,17}$. The intra-class correlation coefficient was used to determine the consistency in the repeated measurements in reading performance evaluation ${ }^{26}$. Reliability and agreement analysis are necessary to estimate the amount of error in the assessment or scoring of tests and classification procedures $^{26}$. Therefore, the higher the ICC values the better reproducibility of the measurement. The ICC value in Cronbach's alpha normally ranges between ' 0 ' to ' 1 '. The closer Cronbach's alpha values to ' 1 ', the greater the consistency. ${ }^{27}$ The reliability was categorizedinto six orders which were $>0.9$ as excellent, $>0.8$ as good, $>0.7$ as acceptable, $>0.6$ as questionable, $>0.5$ as poor and $<0.5$ as unacceptable ${ }^{27}$.

\section{Conclusions}

In conclusion, the study had demonstrated that both the UiTM-Mrw reading chart and the UiTM-Muw reading chart provide good consistency and good agreement in repeated measurements of the reading rate among young adults.

\section{Acknowledgement}

Financial support: Exploratory Research Grant Scheme, Ministry of Education [600-RMI/ERGS 5/3 (59/2012)]

\section{Conflict of interest : None}




\section{References}

1. Coyne KS, Margolis MK, Kennedy-Martin T, et al. The Impact of Diabetic Retinopathy: Perspectives From Patient Focus Groups. Fam Pract. 2004;21(4):447-453. http://dx.doi.org/10.1093/fampra/cmh417

2. Lamoureux EL, Hassell JB, Keeffe JE. The Impact of Diabetic Retinopathy on Participation in Daily Living. Arch Ophthalmol. 2004;122:84-88. http://dx.doi.org/10.1001/archopht.122.1.84

3. Nelson P, Aspinall P, Papasouliotis O, Worton B, O'Brien C. Quality of Life in Glaucoma and Its Relationship with Visual Function. J Glaucoma. 2003;12(2):139-150. http://dx.doi.org/10.1097/00061198-200304000$\underline{00009}$

4. Hariprasad SM, Mieler WF, Grassi M, Green JL, Jager RD, Miller L. Vision-Related Quality of Life in Patients With DiabeticMacularOedema.BrJOphthalmol.2008;92:89-92. http://dx.doi.org/10.1136/bjo.2007.122416

5. Whittaker SG, Lovie-Kitchin JAN. Visual Requirements For Reading. Optom Vis Sci. 1993;70(1):54-65. http://dx.doi.org/10.1097/00006324-199301000$\underline{00010}$

6. Legge GE, Ross JA, Isenberg LM, Lamay JM. Psychophysics of reading. Clinical predictors of low-vision reading speed. Invest Ophthalmol Vis Sci. 1992;33(3):677-687.

7. Hoover WA, Gough PB. The Simple View of Reading. Read Writ. 1990;2:127-160. http://dx.doi.org/10.1007/BF00401799

8. Mansfield JS, Ahn SJ, Legge GE, Luebker A. A new reading-acuity chart for normal and low vision. Ophthalmic Vis Opt. 1993;3:232-235.

9. Wolffsohn JS, Cochrane AL. The practical near acuity chart (PNAC) and prediction of visual ability at near1. Ophthalmic Physiol Opt. 2000;20(2):90-97. http://dx.doi.org/10.1016/S0275-5408(99)00035-6

10. Radner W, Obermayer W, Richter-Mueksch S, Willinger U, Velikay-Parel M, Eisenwort B. The validity and reliability of short German sentences for measuring reading speed. Graefe's Arch Clin Exp Ophthalmol. 2002;240(6):461-467. http://dx.doi.org/10.1007/s00417-002-0443-5

11. Bailey IL, Lovie JE. The design and use of a new nearvision chart. Am J Optom Physiol Opt. 1980;57(6):378-387. Available at: http://europepmc.org/abstract/MED/7406006. http://dx.doi.org/10.1097/00006324-198006000$\underline{00011}$

12. Azizan MF. A new standardized Malay unrelated word near chart. 2010. Bachelor thesis. Universiti Teknologi MARA

13. Buari NH, Chen AH, Musa N. Comparison of reading speed with 3 different log-scaled reading charts. J Optom. 2014.(in press). http://dx.doi.org/10.1016/j.optom.2013.12.009

14. Subramanian A, Pardhan S. The Repeatability of MNREAD Acuity Charts and Variability at Different
Test Distance. Optom Vis Sci. 2006;83(8):572-576. h t t p: //dx.doi.org/10.1097/01. opx.0000232225.00311.53

15. Virgili G, Cordaro C, Bigoni A, Crovato S, Cecchini P, Menchini U. Reading acuity in children: evaluation and reliability using MNREAD charts. Investig Ophthalmol Vis Sci. 2004;45(9):3349-3354. http://dx.doi.org/10.1167/iovs.03-1304

16. Stifter E, König F, Lang T, et al. Reliability of a standardized reading chart system: variance component analysis, test-retest and inter-chart reliability. Graefe's Arch Clin Exp Ophthalmol. 2004;242:31-39. http://dx.doi.org/10.1007/s00417-003-0776-8

17. Maaijwee K, Mulder P, Radner W, Meurs JC. Reliability Testing of the Dutch Version of the Radner Reading Charts. Optom Vis Sci. 2008;85(5):353-358. http://dx.doi.org/10.1097/OPX.0b013e31816bf58b

18. Mataftsi A, Bourtoulamaiou A, Haidich A-B, et al. Development and validation of the Greek version of the MNREAD acuity chart. Clin Exp Optom. 2013;96(1):25-31. http://dx.doi.org/10.1111/j.1444-0938.2012.00799.x

19. Chung STL. The effect of letter spacing on reading speed in central and peripheral vision. Invest Ophthalmol Vis Sci. 2002;43(4):1270-6. Available at: http://www.ncbi.nlm.nih. gov/pubmed/11923275.

20. Corneau E. Study Shows Newspapers ' Front Page Fonts. http://www.poynter.org. 2004. Assessed 1 March 2013

21. Legge GE, Pelli DG, Rubin GS, Schleske MM. Psychophysics of reading--I. Normal vision. Vision Res. 1985;25(2):239-252. http://dx.doi.org/10.1016/0042-6989(85)90117-8

22. Sedgwick P. Limits of agreement (Bland-Altman method). BMJ. 2013;346(f1630):1-2.

23. Bland JM, Altman DG. Statistical methods for assessing agreement between two methods of clinical measurement. Lancet. 1986;1(8476):307-10. http://dx.doi.org/10.1016/S0140-6736(86)90837-8

24. Myles PS, Cui J. Using the Bland-Altman method to measure agreement with repeated measures. $\mathrm{Br}$ J Anaesth. 2007;99(3):309-11. http://dx.doi.org/10.1093/bja/aem214

25. MohammedZ,OmarR.ComparisonofReadingPerformance Between Visually Impaired and Normally Sighted Students in Malaysia. Br J Vis Impair. 2011;29(3):196-207. http://dx.doi.org/10.1177/0264619611415004

26. Kottner J, Audigé L, Brorson S, et al. Guidelines for Reporting Reliability and Agreement Studies (GRRAS) were proposed. J Clin Epidemiol. 2011;64(1):96-106. http://dx.doi.org/10.1016/i.jclinepi.2010.03.002

27. Gliem JA, Gliem RR. Calculating, Interpreting, and Reporting Cronbach 's Alpha Reliability Coefficient for Likert-Type Scales. In: Midwest Research-to-Practice Conference in Adult, Continuing, and Community Education. The Ohio State University, Columbus; 2003:82-88. 